\title{
A Simplified Methodology for Optimal Location and Setting of Valves to Improve Equity in Intermittent Water Distribution Systems
}

\author{
Aurora Gullotta $^{1}$ D $\cdot$ Alberto Campisano ${ }^{1} \cdot$ Enrico Creaco $^{2} \cdot$ Carlo Modica $^{1}$
}

Received: 23 December 2020 / Accepted: 31 August 2021 / Published online: 20 September 2021

(C) The Author(s) 2021

\begin{abstract}
In this paper, a simplified methodology to increase the water distribution equity in existing intermittent water distribution systems (WDSs) is presented. The methodology assumes to install valves in the water distribution network with the objective to re-arrange the flow circulation, thus allowing an improved water distribution among the network users. Valve installation in the WDS is based on the use of algorithms of sequential addition (SA). Two optimization schemes based on SA were developed and tested. The first one allows identifying locations of gate valves in order to maximize the global distribution equity of the network, irrespectively of the local impact of the valves on the supply level of the single nodes. Conversely, the second scheme aims to maximize the global equity of the network by optimizing both location and setting (opening degree) of control valves, to include the impact of the new flow circulation on the supply level of each node. The two optimization schemes were applied to a case study network subject to water shortage conditions. The software EPA Storm Water Management Model (SWMM) was used for the simulations in the wake of previous successful applications for the analysis of intermittent water distribution systems. Results of the application of the SA algorithms were also compared with those from the literature and obtained by the use of the multi-objective Non-Dominated Sorted Genetic Algorithm II (NSGA II). The results show the high performance of SA algorithms in identifying optimal position and settings of the valves in the WDS. The comparison pointed out that SA algorithms are able to perform similarly to NSGA II and, at the same time, to reduce significantly the computational effort associated to the optimization process.
\end{abstract}

Keywords Intermittent water distribution systems · Private tanks · Equity · EPA-SWMM · Sequential addition algorithm $\cdot$ Control valves

\section{Introduction}

Intermittency in water supply is increasingly adopted both in developing and developed countries around the world (McIntosh and Yñiguez 1997; Hardory et al. 2001; Vairavamoorthy et al. 2007; Andey and Kelkar 2009; Mohapatra et al. 2014; Agathoklis and Christodoulou 2016; Galaitsi et al. 2016; Simukonda et al. 2018).

Aurora Gullotta

aurora.gullotta@unict.it

Extended author information available on the last page of the article 
Intermittent Water Distribution Systems (WDSs) are never a design choice. A common scenario is that most WDSs initially provide water continuously; however, their ability to satisfy the users' demand is later limited by unpredicted changes (Kumpel and Nelson 2015). Under intermittent conditions, WDSs can supply water for periods less than 7 days a week and/or for less than $24 \mathrm{~h}$ a day. Alternatively, they can supply water for the whole $24 \mathrm{~h}$ but making only a fraction of the water daily demand available. In both cases, the WDS behaves as an intermittent system, with cyclical phases of network filling/emptying and users that may have access to water in a discontinuous way (Ameyaw et al. 2013; Gullotta et al. 2021).

Environmental constraints such as the scarcity of the water resource are often put forward by water service companies as the primary explanation for intermittent operation. However, such constraints represent only one aspect of the problem, which is, instead, multi-dimensional; indeed, overemphasis on resource constraints risks under-valuing the human drivers that may contribute significantly in determining intermittent water supply. Moreover, the analysis of the causal-consequential pathways of such systems highlights that intermittency in water supply has consequences that reinforce its causes in a sort of complex negative feedback loop (Galaitsi et al. 2016).

Impacts of intermittency in water distribution are several and affect both water quantity and quality as well as the status of the water supply infrastructure itself (Klingel 2012; Simukonda et al. 2018). One of the highest social costs of intermittent WDSs is the resulting inequity in water distribution among the network users. The inequity in water allocation to users depends on the lack of uniform distribution of the pressure in the network nodes. Indeed, the topological layout of the network can determine advantages for some nodes of the WDS with respect to other nodes, because of their elevation or their proximity to the supply reservoir (Fontanazza et al. 2007; Ameyaw et al. 2013). In the practice, this implies different water reception time (the time needed for water to travel from the source to the node) for the different nodes of the network (Mokssit 2018). Actually, it is not unusual that the reception time for some nodes may be greater than the supply duration, thus determining disadvantages for users supplied by such nodes.

Several authors (e.g. Arregui et al. 2006; Cobacho et al. 2008; Criminisi et al. 2009) have shown that the water supply performance of intermittent WDSs may be worsened by the presence of private tanks at the household level (i.e. roof or basement tanks). Such tanks are progressively installed by the end users with the objective to store water volumes as back-up source for non-supply hours. Private tanks introduce additional complexity to the network and increase inequity in water distribution. Actually, the presence of tanks (that are potentially empty) causes the increase in peak flows, which, in turn, determine higher head losses in the network and increased pressure differences between the nodes (Mokssit 2018; Fontanazza et al. 2007). De Marchis et al. (2011) analysed the spatial and temporal non-homogeneity of the water distribution in a WDS in southern Italy with private tanks installed at the household level. Interestingly, results of this analysis show that private tanks always increase water distribution inequity, even when the available water resource is sufficient to fully satisfy the demand. As a result, some users get more water than others being privileged by a higher level of water demand satisfaction.

The research on strategies to improve equity in water distribution in intermittent WDSs has mainly started in the last decade. Most of the strategies are based on the use of optimization methods. For instance, Ameyaw et al. (2013) used a multi-objective optimisation model to maximize equity and minimize the costs of water distribution by varying the size and the location of users' private tanks. Model results showed that the maximum equity level is associated with the highest total cost and vice-versa. Gottipati and Nanduri 
(2014) have shown that the equity in intermittent water distribution is affected by multiple factors. Among these factors, the authors include water levels at the supply reservoir, the demand pattern at the network nodes, the diameter of the pipes, as well as the structure of the network. Ilaya-Ayza et al. (2017a; b) performed a multi-criteria analysis for the optimization of the supply schedule in intermittent WDNs by taking into account equity issues; they demonstrated the benefits of creating district-metered areas (DMA) in the network to improve intermittent supply schedules. Although the strategies described above provide improvement in the water distribution, most of them require implementing radical changes in the network layout. Therefore, this means that their practical application to real systems may be carried out at affordable costs only in the planning/design or in the longterm upgrade stages of WDSs.

More recently, alternative approaches to improve water distribution equity in existing intermittent WDSs at low cost of implementation have been suggested in the literature. Some of these approaches are based on the installation of control valves or other control devices in the network. Gullotta et al. (2021) proposed a methodology to identify optimal sites and settings of control valves in the network to re-arrange flow circulation into pipes with the aim of improving the equity in water distribution among the users. The authors developed specific multi-objective genetic algorithms based on the Non-Dominated Sorted Genetic Algorithm II (NSGA II) (Deb et al. 2002). These algorithms were applied in combination with EPA Storm Water Management Model (SWMM), which was used to simulate the network under different configurations of installation of the control valves (Campisano et al. 2018). An application of the methodology was carried out on a WDS in northern Italy by considering water shortage scenarios and users equipped with private storage tanks. The results of the application demonstrated the potential of the approach in increasing the global level of equity in the network. However, the computational time needed for the optimization process was rather high, thus representing a limitation for the application of the methodology to large networks.

In order to overcome this limitation, this paper proposes a novel simplified methodology aimed at finding optimal locations and settings of control valves to improve equity in intermittent WDSs. The proposed methodology is based on a single-objective algorithm of Sequential Addition (SA) of the control valves in the network. The developed algorithm was combined with EPA-SWMM (Cabrera-Bejar and Tzatchkov 2009; Manish and Buchberger 2012) and its performance was tested through the application to the same network proposed by Gullotta et al. (2021), in order to allow comparison between SA and NSGA II algorithms.

The proposed method is innovative in combining the simple SA optimization algorithm with EPA-SWMM for the study of the emptying and filling phases of intermittent networks. Also the comparison between results of application of SA and NSGA II algorithms for intermittent WDSs is novel. As compared to the NSGA II algorithm, the SA algorithm allows to obtain excellent results in rebalancing the water distribution in the network with a very limited calculation effort.

\section{Methodology}

\subsection{Evaluation of Equity in Water Distribution}

The developed Sequential Addition (SA) algorithms are finalized at improving equity in water distribution among users of intermittent WDSs. 
Evaluation of the water distribution equity was carried out using the uniformity coefficient (UC) proposed by Gottipati and Nanduri (2014):

$$
U C=1-\frac{A D E V}{A S R}
$$

In Eq. (1) $A S R=\sum S R / n$ is the daily average of the supply ratios $S R$ of the $n$ network demand nodes (nodal $S R$ are provided by the ratio of the supplied water volume to the demand volume), and $A D E V=\sum|S R-A S R| / n$ is the daily average of absolute deviations (from $A S R$ ) of the supply ratios of the $n$ demand nodes in the WDN. $U C$ ranges from 0 (minimum level of equity) to 1 (maximum level of equity). Unlike other indicators that have been proposed in the literature (Fontanazza et al. 2007; De Marchis et al. 2011), UC does not depend on the considered water shortage scenario. In fact, $U C=1 \mathrm{can}$ be obtained even in scenarios of water shortage if all the nodes of the network perform with the same value of $S R<1$. As an example of this, let us consider a condition of water rationing with total supply equal to $70 \%$ of the total network demand. If all the nodes are assumed to receive the same level of service (same $S R$ ), the maximum value of the supply ratio for the nodes is $S R=0.7$. Therefore, values of $A D E V=0$ and $U C=1$ are obtained by use of Eq. (1). In these cases of water shortage, the value of $S R$ in the condition of maximum equity may be considered as an "equity threshold" $(E T)$ for all the network users.

Importantly, calculation of the value of $U C$ through simulation of the network needs considering that intermittent WDSs are cyclically subject to transitory phases in the water supply (Campisano et al. 2018). The alternate processes of filling and emptying of the network are always characterised by transitory conditions of unbalance between input and output flows. Transitory phases may have duration of several days before a condition of regime is achieved (Gullotta et al. 2021). For this reason, all the simulations presented in this work were run up to the achievement of the condition of regime, that was considered to be achieved when the daily values of $S R$ and $U C$ do not change anymore during the simulation.

\subsection{SA Algorithms}

The SA algorithms proposed in this paper stem from the works of Pezzinga and Gueli (1999) and Creaco and Pezzinga (2018), concerning SA of valves in continuous water supply systems. The denomination SA was first proposed by Creaco and Pezzinga (2018) in order to describe that the optimal site in the network for each valve is identified in a sequential way. Specifically, the position of the $i$-th valve is searched by the algorithm, while keeping fixed location of the $i$-1-th valve previously identified.

In this research, two SA optimization schemes were developed and applied to intermittent WDSs in a novel way. The first scheme assumes to install fully closed valves (e.g. gate valves) in the network to change the flow circulation in order to maximize $U C$. This scheme does not consider the local impact of the new flow circulation on the level of supply satisfaction at each network node. Instead, the second optimization scheme aims to maximize $U C$ by optimizing both location and settings of control valves, while also taking into account the effect of the new flow circulation on the supply level at each node.

EPA-SWMM software was used for the hydraulic simulations (Rossman 2015). The software is able to model the switch from free surface to under-pressure flows and 
vice-versa. Therefore, although originally developed for the analysis of urban drainage systems, it has demonstrated to simulate properly the intermittent behaviour of WDSs also in the description of the filling and emptying phases of the network (Campisano et al. 2018; Gullotta et al. 2021). A detailed description of the two SA optimization schemes is reported in the following paragraphs.

\subsubsection{SA of Gate Valves}

The rationale behind the use of the first SA optimization scheme is to modify the flow circulation in the WDS by using gate valves with the aim to maximize the daily value of $U C$. The algorithm is based on the following steps:

1. The preliminary hydraulic simulation of the WDS without valves is carried out (no-valve scenario) using EPA-SWMM, and the daily value of $U C$ is calculated using Eq. (1);

2. Gate valves are placed in the network one at a time assuming that they are fully closed. A set of $n_{p}$ (number of possible locations of gate valves in the network) simulations is carried out to search for the location of the first valve (valve 1) in the network that provides the largest daily value of $U C$. The value of $n_{p}$ usually coincides with the number of network pipes, unless specific pipes have to be excluded a priori from the set of potential locations of the gate valve (for example the outflow pipe from the supply reservoir or some isolated pipes);

3. $n_{p}-1$ simulations are carried out to search for the location of the second gate valve (valve 2) that provides the largest daily value of $U C$ (being valve 1 already placed in the network according to step 2). In other words, all the pipes are evaluated as potential locations for valve 2 , excluding the pipe selected for installing valve 1 ;

4. Step 3 is repeated to maximize the value of $U C$ until benefits of adding sequentially other gate valves (in terms of increase in $U C$ ) become negligible (increase in $U C$ smaller than $1 \%$ ).

Gate valves were modelled in EPA-SWMM by setting as "closed" the status of the conduits in which they are assumed to be placed (by use of the control rules editor of the software, see Gullotta et al. 2021 for details).

This algorithm seeks to improve the global equity of the water distribution in the WDS. However, it does not take into account potential unfair decrease in single $S R$ values (i.e. at the level of the single node) with respect to the no-valve scenario.

\subsubsection{SA of Control Valves}

The second SA optimization scheme aims to identify both locations and closure settings of control valves. Such valves are placed and set in the network in order to maximize $U C$, while respecting local constraints concerning acceptable changes of nodal $S R$. Acceptable values of $S R$ are different for nodes starting with $S R>E T$ or $S R<E T$ in the no-valve scenario. Nodes with $S R>E T$ (with an excess of supply as compared to the equity threshold) can undergo the $S R$ decrease down to $E T$ in the configuration with valves installed. Instead, nodes with $S R<E T$ are not allowed to further reduce their value of $S R$ since this would sharpen inequity in water supply at such nodes. The operational steps to implement the algorithm are as follows: 
1. The simulation of the network without valves installed is carried out as for step 1 of the procedure reported at previous Sect. 2.2.1;

2. Similarly to step 2 of the previous procedure, pipe-by-pipe simulations are carried out assuming control valve 1 to be located alternatively in one of the $n_{p}$ possible locations in the network. Preliminarily, the control valve is assumed to be fully closed. Priority of location of the valves is identified according to the obtained values of $U C$ (one for each simulation), which are ranked in decreasing order;

3. The first location in the ranking list is considered and each node of the network is analysed to check if the placement of the valve does not result in unacceptable values of the nodal $S R$;

4. If the nodal check is not passed for one or more nodes of the network, targeted simulations are run to evaluate if other closure settings with the same valve location can mitigate local negative impacts on the nodal $S R$. Operationally, the simulations are carried out with increasing the valve opening until all the nodes of the network achieve acceptable values of $S R$. Conversely, if the check is still not satisfied for any of the settings of the valve, the first location in the list is discarded and the procedure is repeated (starting from step 3) for the second location in the rank;

5. SA of control valve 2 is carried out by repeating the same steps, assuming valve 1 being already placed and set as for previous steps 3 and 4. As for Sect. 2.2.1, all the pipes are evaluated as potential locations for valve 2 , excluding the pipe already identified for the installation of valve 1 ;

6. The procedure is terminated when SA of control valves does not provide further significant benefits in terms of $U C$ (i.e. increase $<1 \%$ ).

Simulation of control valves with different closure degree in EPA-SWMM was carried out by use of an entry loss coefficient $K(-)$ for conduits in which the valves were installed (see details in Gullotta et al. 2021). The head loss $\Delta H(\mathrm{~m})$ provided by the valve is evaluated by the model as:

$$
\Delta H=K \frac{V^{2}}{2 g}
$$

being $V(\mathrm{~m} / \mathrm{s})$ the velocity of the flow entering the conduit. The range of values of $K$ used for the simulations was determined as a function of the valve degree of closure based on data provided by valve manufacturers.

\section{Case Study}

The proposed methodology was applied to the case study WDS of a small village in northern Italy. The case study is the same used by Gullotta et al. (2021) for the application of algorithms based on the use of NSGA II. The network (Fig. 1) was also used in the past for the analysis of demand and leakages in WDSs (Farina et al. 2014; Creaco and Walski 2017). It consists of 26 nodes (of whom 25 are demand nodes), one source node (supply reservoir), and 32 pipes. The nodes of the network are at the same elevation, $35 \mathrm{~m}$ below the source node. The network daily average demand is $50.49 \mathrm{~L} / \mathrm{s}$. Tables 1 and 2 provide the nodal average daily demands and the main characteristics (length and diameter) of the pipes (also reported in Creaco and Walski 2017). All the 


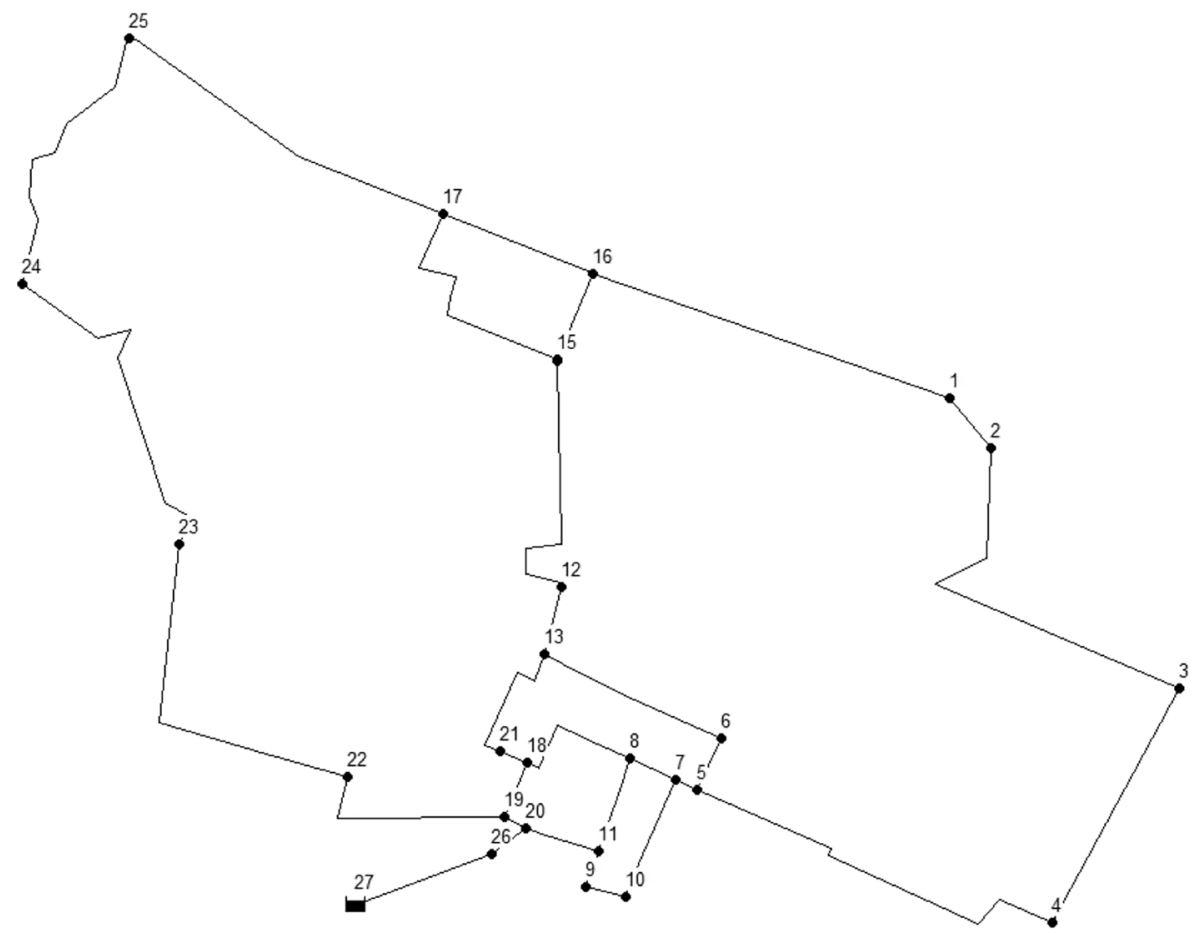

Fig. 1 Layout of the network

pipes are in PVC and are assumed to have value of the Manning roughness coefficient of $0.01 \mathrm{~s} / \mathrm{m}^{1 / 3}$.

The simulations were run considering that the households of the network are equipped with private tanks ( $250 \mathrm{~L}$ per person) to cope with supply scenarios of water shortage. EPA-SWMM was used for the hydraulic simulation of the network in all the potential configurations of valve installation. Private tanks interposed between the network nodes and the users were modelled in EPA-SWMM as explained in Gullotta et al. (2021) by using "equivalent" tanks that simulate groups of private tanks belonging to the same node of the network (De Marchis et al. 2010; 2014; 2015). Globally, 25 equivalent tanks (one per demand node) were considered. Installation of such tanks was assumed below the ground level (typical configuration with the tank placed in the house basement). The capacity of each tank was calculated based on the total population supplied by the corresponding network node. The daily pattern (demand multipliers) reported in Fig. 2 was used to model the demand outflow from the equivalent tanks.

Conditions of water supply rationing due to water shortage were considered. Specifically, a fraction equal to $70 \%(35.34 \mathrm{l} / \mathrm{s})$ of the total daily water demand was supplied to the network continuously for the $24 \mathrm{~h}$. Under the depicted scenario, the equity threshold value of ET is equal to 0.7. Therefore, equitable management of the available water resource would assume that nodes with $S R>0.7$ should undergo the water supply reduction in favour of those nodes that have $S R<0.7$. 
Table 1 Case study. Nodal average daily demands

\begin{tabular}{|c|c|}
\hline Node & $\begin{array}{l}\text { Daily } \\
\text { demand } \\
(1 / \mathrm{s})\end{array}$ \\
\hline 1 & 1.38 \\
\hline 2 & 0.18 \\
\hline 3 & 0.92 \\
\hline 4 & 2.57 \\
\hline 5 & 2.83 \\
\hline 6 & 8.36 \\
\hline 7 & 3.42 \\
\hline 8 & 5.33 \\
\hline 9 & 1.52 \\
\hline 10 & 0.86 \\
\hline 11 & 2.27 \\
\hline 12 & 1.31 \\
\hline 13 & 8.52 \\
\hline 14 & 0.88 \\
\hline 15 & 0.22 \\
\hline 16 & 0.39 \\
\hline 17 & 0.45 \\
\hline 18 & 2.82 \\
\hline 19 & 0.03 \\
\hline 20 & 0.31 \\
\hline 21 & 2.60 \\
\hline 22 & 1.03 \\
\hline 23 & 1.00 \\
\hline 24 & 0.53 \\
\hline 25 & 0.76 \\
\hline 26 & 0.00 \\
\hline 27 & 0.00 \\
\hline
\end{tabular}

The simulations were carried out assuming that the network pipes (as well as the equivalent tanks) are initially empty. This initial condition allows considering heavy scenarios of water shortage (e.g. the restart of the system supply after the occurrence of a malfunctioning of the pumps at the source reservoir). EPA-SWMM was applied using a time step of simulation $\Delta t=10 \mathrm{~s}$ and assuming a maximum value of the spatial step $\Delta x=100 \mathrm{~m}$ for all the simulations. The chosen spatial scale value was proven to be sufficiently small to provide accurate results in the description of the dynamics of the processes of intermittency (Campisano et al. 2018).

\section{Results and Discussion}

\subsection{Simulation of the No-Valve Scenario}

The behaviour of the WDS was preliminary explored in the scenario without valves installed. The simulation of this scenario was used as a reference for the solutions provided 
Table 2 Case study. Network pipe characteristics

\begin{tabular}{|c|c|c|c|c|}
\hline Pipe & Up node & Down node & $L(\mathrm{~m})$ & $D(\mathrm{~mm})$ \\
\hline 1 & 1 & 2 & 10.1 & 100 \\
\hline 2 & 2 & 3 & 2874.5 & 125 \\
\hline 3 & 3 & 4 & 1732.8 & 150 \\
\hline 4 & 1 & 16 & 2851.4 & 125 \\
\hline 5 & 4 & 5 & 2648 & 200 \\
\hline 6 & 5 & 7 & 144.5 & 200 \\
\hline 7 & 5 & 6 & 364.9 & 200 \\
\hline 8 & 7 & 10 & 817.4 & 150 \\
\hline 9 & 6 & 13 & 1269.8 & 200 \\
\hline 10 & 7 & 8 & 332.7 & 300 \\
\hline 11 & 8 & 11 & 628.3 & 150 \\
\hline 12 & 9 & 10 & 269.7 & 150 \\
\hline 13 & 11 & 9 & 241.3 & 150 \\
\hline 14 & 8 & 18 & 887.8 & 300 \\
\hline 15 & 12 & 14 & 2055.9 & 150 \\
\hline 16 & 13 & 12 & 130.9 & 250 \\
\hline 17 & 21 & 13 & 991.1 & 250 \\
\hline 18 & 14 & 15 & 6.8 & 200 \\
\hline 19 & 15 & 16 & 607.2 & 150 \\
\hline 20 & 15 & 17 & 1669.7 & 125 \\
\hline 21 & 17 & 16 & 1046.8 & 150 \\
\hline 22 & 18 & 21 & 132.1 & 300 \\
\hline 23 & 18 & 19 & 392.5 & 450 \\
\hline 24 & 19 & 20 & 154.5 & 450 \\
\hline 25 & 22 & 23 & 2469.3 & 200 \\
\hline 26 & 22 & 19 & 1593.6 & 250 \\
\hline 27 & 24 & 23 & 2567 & 125 \\
\hline 28 & 25 & 24 & 2337.7 & 100 \\
\hline 29 & 17 & 25 & 2452.7 & 150 \\
\hline 30 & 27 & 26 & 19.6 & 450 \\
\hline 31 & 26 & 20 & 9.6 & 450 \\
\hline 32 & 20 & 11 & 490.9 & 150 \\
\hline
\end{tabular}

later by the optimization algorithms. The results of this simulation are reported in Table 3 and show a very low level of uniformity in water distribution in the network. The table highlights that 13 nodes out of 25 provide full satisfaction of the users' demand (i.e. $S R=1.0$ ), while users of seven nodes do not have access to water at all $(S R=0)$, and 4 nodes can achieve $S R$ values smaller than the $E T(S R<0.7)$. Only 1 node has a $0.7<S R<1.0$ (node 13 with $S R=0.9$ ). The $U C$ coefficient shows a global level of equity equal to 0.26 .

The analysis of the results provided by Gullotta et al. (2021) reveal that the low level of equity in water distribution in the analysed network is highly impacted by the presence of the equivalent tanks. For example, this is pointed out in Fig. 3. The Figure shows that the value of $U C$ at the condition of regime decreases from 1.0 (simulation without equivalent tanks) down to the value 0.26 (simulation with equivalent tanks installed). As early explained, the general trend of the curve of $U C$ reflects the impact of the initial conditions of the network on the results of the simulation with the value at regime achieved after 
Fig. 2 Daily pattern of the nodal water demands in the network



about 7 days from the beginning of the water supply period. In this concern, simulations allowed establishing that a duration of 14 days was sufficient to assure the achievement of the condition of regime for all the configurations explored in this work.

\subsection{Application of the SA Algorithms}

The application of the first SA optimization scheme described at sub-section 2.2 led to identify pipe between nodes 18 and 19 as the optimal site to place the first gate valve; the algorithm provided second and third gate valves in pipes between nodes 8 and 11, and between nodes 12 and 14, respectively. Instead, the addition of further valves in the network provided negligible increase in the value of $U C$. Figure 4 summarizes the results of the application of the algorithm in terms of value of $U C$ achieved by the sequential addition of the gate valves. The figure shows that the installation of the first gate valve in the network may provide a significant increase in the equity of the water distribution with $U C$ growing from 0.26 to 0.66 . The value of the coefficient grows up to 0.75 and 0.78 in the configurations with 2 and 3 gate valves, respectively. Indeed, the benefit of adding further valves is small because the addition of the fourth valve may provide negligible increase in $U C$.

Table 3 reports nodal $S R$ values as obtained in the solution with 3 gate valves and the comparison with the corresponding values in the no-valve scenario. The re-arrangement of the flow circulation in the network induced by the valves allows increasing the level of global equity among the users of the network. This is demonstrated by the increment of $U C$ from 0.26 to 0.78 due to more uniform nodal $S R$ values as compared to the no-valve scenario. Going into details of the single nodes, some of them (nodes from 1 to 4, 6, from 14 to 17 , and 25) increase their $S R$, while other nodes (nodes 5, from 7 to 11 , from 18 to 20 , from 22 to 24) are not impacted by the installation of the valves. The detailed analysis of the simulation results shows that the gate valves act by forcing flows to change their original paths, and to reach also nodes in the external loop of the network that were not previously supplied (this is the case of nodes from 1 to 4 , 6, from 14 to 17 , and 25 that did not receive water at all or that were under supplied in the no-valve scenario). However, 
Table 3 Nodal $S R$ values in the no-valve scenario and in the solutions with 3 gate valves and with 4 control valves provided by SA algorithms

\begin{tabular}{llll}
\hline Node & SR no-valve & SR 3 gate valves & $\begin{array}{l}\text { SR 4 control } \\
\text { valves }\end{array}$ \\
\hline 1 & 0.0 & 1.0 & 0.3 \\
2 & 0.0 & 1.0 & 0.0 \\
3 & 0.0 & 1.0 & 0.0 \\
4 & 0.2 & 0.8 & 0.2 \\
5 & 1.0 & 1.0 & 0.8 \\
6 & 0.2 & 0.5 & 0.2 \\
7 & 1.0 & 1.0 & 1.0 \\
8 & 1.0 & 1.0 & 1.0 \\
9 & 1.0 & 1.0 & 1.0 \\
10 & 1.0 & 1.0 & 1.0 \\
11 & 1.0 & 1.0 & 1.0 \\
12 & 0.3 & 0.0 & 0.6 \\
13 & 0.9 & 0.1 & 0.8 \\
14 & 0.0 & 1.0 & 1.0 \\
15 & 0.0 & 1.0 & 1.0 \\
16 & 0.0 & 1.0 & 1.0 \\
17 & 0.0 & 1.0 & 1.0 \\
18 & 1.0 & 1.0 & 1.0 \\
19 & 1.0 & 1.0 & 1.0 \\
20 & 1.0 & 1.0 & 1.0 \\
21 & 1.0 & 0.7 & 1.0 \\
22 & 1.0 & 1.0 & 1.0 \\
23 & 1.0 & 1.0 & 1.0 \\
24 & 1.0 & 1.0 & 1.0 \\
25 & 0.4 & 1.0 & 1.0 \\
\hline & & &
\end{tabular}

the re-distribution of the flows results in the decrease in $S R$ down to 0.7 for two nodes (nodes 12 and 13 that reduce from 0.3 to 0 and from 0.9 to 0.1 , respectively). As already discussed, this may be a limitation in the application of the first SA optimization scheme. Indeed, some nodes of the WDS could "pay" with unacceptable decrease in their local SR to allow the increase in the global equity of the network. Potentially, such condition could represent reason of complaints by users supplied by those nodes, unless specific local supply countermeasures are not implemented by the network manager together with valves installation. Remarkably, also node 21 shows $S R$ to decrease, although the value of $S R$ at regime is acceptable as it remains over the ET value of 0.7 .

Figure 5 summarizes the results of the application of the SA algorithm with control valves (second SA optimization scheme described in sub-section 2.2). As expected, the pattern of $U C$ as a function of the number of valves installed features lower values as compared with the first SA optimization scheme. The application of the second SA algorithm provided optimal configuration with 4 control valves in the network: valve $1(K=125)$ in the pipe between nodes 7 and 8, valve 2 (gate valve) in the pipe between nodes 6 and 13, valve $3(K=2000)$ in the pipe between nodes 9 and 11 , and valve $4(K=60,000)$ in the pipe between nodes 18 and 19 . The introduction of a fifth valve did not provide further significant increase in $U C$. 
Fig. 3 Simulation of the network in the no-valve scenario with and without private tanks. Value of $U C$ as a function of the simulation time

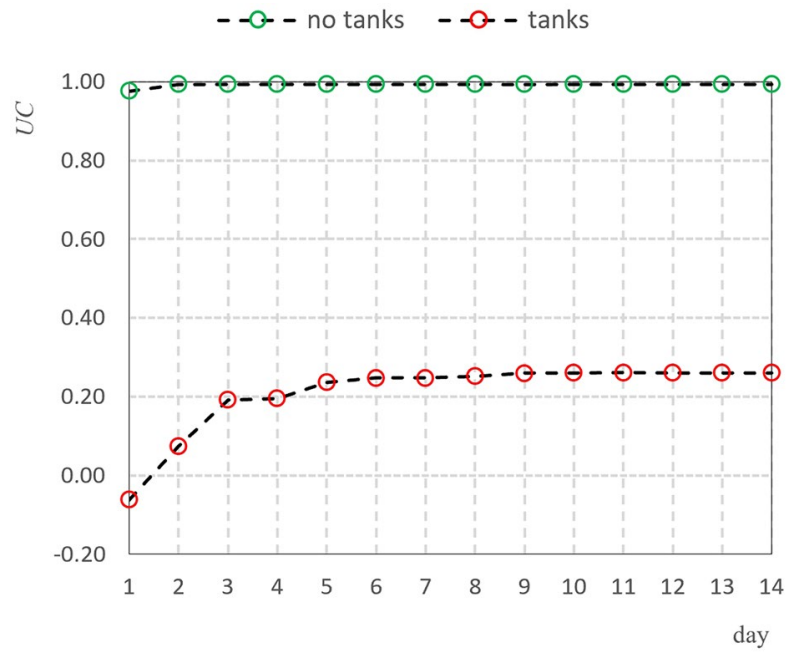

The figure shows that the value of $U C$ achieved with 4 control valves is 0.65 . Remarkably, this value is lower than the value of $U C$ obtained with 3 gate valves by adopting the first SA optimization scheme (see Fig. 4). However, Fig. 3 shows that the second scheme allows avoiding local negative impacts due to the change of flow circulation. The table reports nodal SR values at regime for the 25 demand nodes of the network as obtained with the 4 control valves, and the comparison of these values with $S R$ values in the no-valve scenario. The results show that nodes 1,12 , nodes $14-17$, and node 25 improve their $S R$ value. Other nodes (nodes 2-4, 6-11, and 18-24) are not impacted by the installation of the valves. Finally, nodes 5 and 13 reduce their SR value (from 1.0 and 0.9 to 0.8 , respectively), although they always remain over the ET threshold of 0.7 . As expected, the second SA optimization scheme did not provide a decrease in $S R$ values below the ET threshold.

Fig. 4 Results of SA of gate valves. Values of UC as a function of the number of gate valves

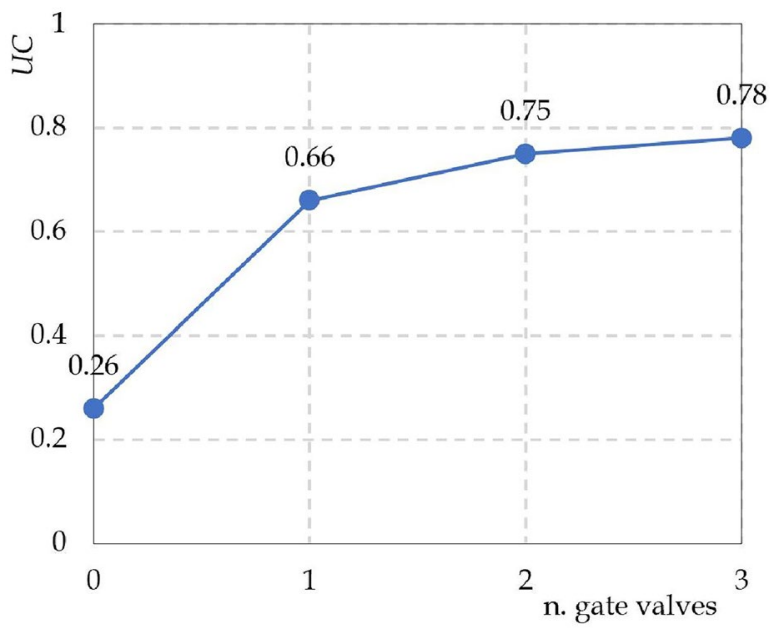


Fig. 5 Results of SA of control valves. Values of $U C$ as a function of the number of valves

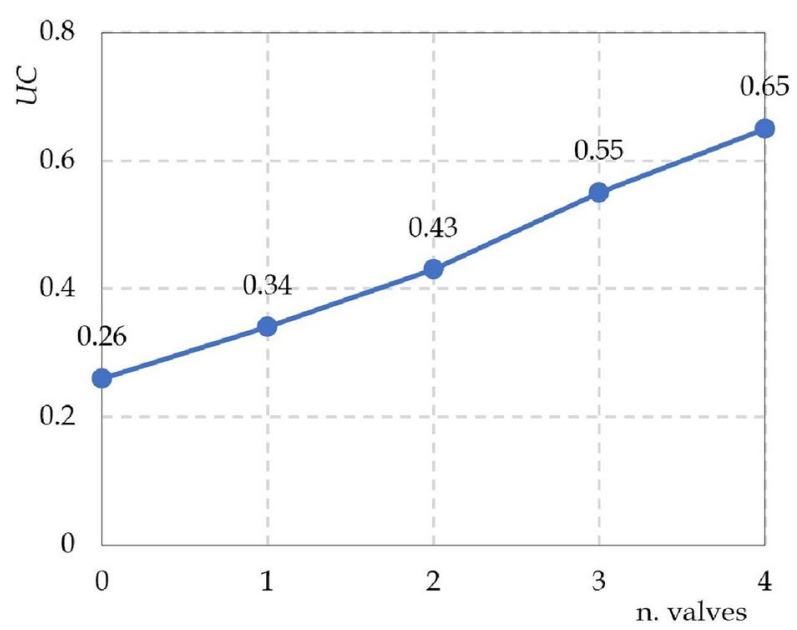

\subsection{Comparison with NSGA II}

The results reported in the previous sections show that SA algorithms allow for identifying optimal locations and settings of control valves to increase equity in water distribution among the users of intermittent WDSs.

A specific discussion is deserved on the comparison of the results with those by Gullotta et al. (2021) obtained using the NSGA II multi-objective algorithm. The NSGA II was applied to reduce inequity in the water distribution in the same WDS and at the same conditions that were assumed for the application of the SA algorithm. Specifically, the NSGA II was used for the optimization of the valve positions in the network and for the simultaneous optimization of both position and setting of control valves. On the one hand, the use of the NSGA II multi-objective algorithm allows performing a wider exploration of the research domain space as compared to SA algorithms. Indeed, as a matter of principle, algorithms based on SA may determine trapping in local optimal solutions, due to the research space reduction resulting from the SA. On the other hand, exploring the whole research space of valve locations/settings by use of the NSGA II proved to involve much higher computational efforts than the SA algorithms. This may represent an important advantage for SA algorithms, expecially in the case of application to large networks where excess in computational time can practically prevent NSGA II from achieving a solution in reasonable times. The comparison of the results obtained with the two approaches may help in clarifying this concept. Figure 6 reports results provided by the SA algorithms and NSGA II in terms of values of $U C$ obtained for the two optimization schemes that where considered in this paper (use of gate valves and use of control valves).

Figure 6a points out that, in the first optimization scheme, the SA algorithm performs identically to the NSGA II in the case with one gate valve. The two algorithms provide the same optimal solution with the gate valve being placed in the pipe between nodes 18-19. Conversely, the NSGA II algorithm performs better than the SA algorithm when multiple valves are considered. Indeed, the genetic algorithm allows obtaining a value of $U C=0.86$ in the case of 2 valves installed while the SA algorithm provides $U C=0.75$. Remarkably, even the value of the equity coefficient obtained with a solution with 3 gate valves found 
a)



b)

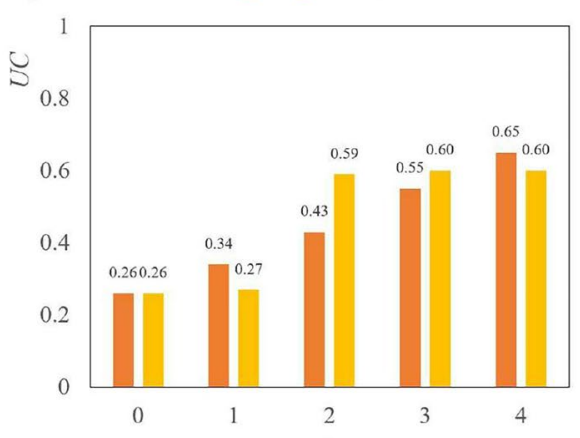

n. valves

Fig. 6 Values of $U C$ obtained with SA algorithms and NSGA II for a optimization scheme with gate valves and $\mathbf{b}$ optimization scheme with control valves

by the SA algorithm $(U C=0.78)$ remains smaller than the value of $U C$ provided by the genetic algorithm with 2 valves only.

Evidently, the lower performance of the SA algorithm is determined by the intrinsic limitations associated to this simplified approach. Indeed, the way the position of the valves in the network is determined (see sections. 2.2.1 and 2.2.2) reduces significantly the size of the research space, thus preventing the algorithm to explore all the potential configurations of valves in the network.

However, as the calculation effort is concerned, the first SA algorithm is very efficient in saving calculation time. The solution of the optimal positioning of 3 gate valves was obtained in about $5 \mathrm{~h}$ simulation. In contrast, the NSGA II algorithm took about 15 days to optimize the positioning of 2 gate valves only.

Figure $6 \mathrm{~b}$ concerns the comparison of SA and NSGA II for the second optimization scheme (control valves with different closure settings). The figure shows that,with one control valve the SA algorithm performs better than NSGA II $(U C=0.34$ against $U C=0.27)$. Oppositely, the NSGA II algorithm performs better than the SA algorithm with 2 control valves $(U C=0.59$ against $U C=0.43)$ and with 3 control valves $(U C=0.60$ against $U C=0.55)$. Remarkably, the simulation with 4 valves reveals a better performance of the SA algorithm in comparison to the NSGA II $(U C=0.65$ against $U C=0.60)$.

Benefits of using the NSGA II do not increase further in the solutions with more than 2 valves. This apparently surprising result reveals that for this second optimization schemes, the research space of NSGA II is also limited. Indeed, as discussed in Gullotta et al. (2021), the methodology based on the use of NSGA II was found to be appliable (with an affordable computational effort) only if a discrete number of control valves settings is provided as input to the algorithm simulation (set of $3 \mathrm{~K}$-values in the application showed in Fig. 6). Conversely, the SA algorithm is free to explore a wider range of valve settings because the $K$-values are not required to be defined a priori. In line of principle, this implies that SA may improve the solution in comparison to the genetic algorithm. This result would confirm that, at least for the analysed case study, use of simplified SA algorithms can be competitive to the NSGA II algorithm in terms of performance. In any case, further research is needed in the future to explore the application of the proposed algorithms to other case study networks, thus shedding light on the general validity of the results obtained in this paper. 
Finally, as the computational effort is considered, the second optimization scheme of the SA algorithm provided to be very efficient in saving time of computation. Indeed, the optimization of the positioning of 4 control valves took $10 \mathrm{~h}$ only. In contrast, the NSGA II algorithm for the same case and with a limited set of $3 \mathrm{~K}$-values required 55 days for the whole simulation.

\section{Conclusions}

The paper presents the results of a novel methodology aimed at increasing the water distribution equity among users of intermittent water distribution systems characterized by water shortage conditions. The methodology is based on the use of algorithms of sequential addition (SA) for the optimal location and setting of control valves in the network with the aim of modify the circulation of flows and improve the water distribution among the network users. Two optimization schemes were set-up. The first scheme considers installation of fully closed valves (i.e. gate valves) and aims at maximizing the global equity in the network, irrespectively of the local impact on the supply level at the single network node. The second optimization scheme aims at maximizing the equity in the network though optimization of both location and setting of partially open valves, while also considering the impact on the supply at each node of the network. The methodology considers also the impact of the presence of private tanks installed at the household level on the flow circulation in the WDS (thus, on the uniformity of the water distribution among network nodes). Hydraulic simulations were carried out using EPA-SWMM software in the wake of the previous successful applications of this software to intermittent WDSs.

The methodology was applied to a real water distribution network in northern Italy in order to evaluate the performance of the proposed SA algorithms in improving equity in water distribution. Results of the application of the SA algorithms were also compared with those from the literature (Gullotta et al. 2021) and obtained by the use of the multiobjective Non-Dominated Sorted Genetic Algorithm II (NSGA II). Globally, the results show the high performance of SA algorithms in identifying optimal position and settings of the valves in the WDS. The application of the first scheme of SA yielded increasing values of the equity coefficient from 0.26 (no-valve scenario) to 0.78 (three-valve solution). However, some network nodes were penalized by the introduction of the valves, because of their supply level decreased unacceptably. As compared to the first scheme, the second scheme of SA provided lower values of the equity coefficient with the same number of valves. Results also pointed out that NSGA II always performs slightly better than the first SA optimization scheme in which NSGA II can efficiently explore the whole research space of combinations of valve locations (i.e. NSGA II identifies solutions with higher values of the equity coefficient). However, the SA algorithm provides higher values of the equity coefficient in the second optimization scheme. As compared to the NSGA II, the SA algorithms allowed reducing significantly the computational effort involved for the optimization process. This suggests promoting the use of the developed optimization schemes for optimal valve positioning and setting in intermittent water distribution systems of large size. The results of this work in terms of comparison between NSGAII and SA will be corroborated through tests against other case studies in future works. 
Authors Contributions AG: Conceptualization, Methodology, Software, Writing-review and editing. AC: Conceptualization, Methodology, Writing — review and editing. EC: Conceptualization, Methodology, Writingreview. CM: Conceptualization, Methodology, Writing—review.

Funding Open access funding provided by Università degli Studi di Catania within the CRUI-CARE Agreement. The authors have no relevant financial or non-financial interests to disclose.

Data Availability The authors confirm that the data supporting the findings of this study are available within the article.

\section{Declarations}

Ethical Approval Not applicable.

Consent to Participate Not applicable.

Consent to Publish Not applicable.

Conflict of Interest The authors have no conflicts of interest to declare that are relevant to the content of this article.

Open Access This article is licensed under a Creative Commons Attribution 4.0 International License, which permits use, sharing, adaptation, distribution and reproduction in any medium or format, as long as you give appropriate credit to the original author(s) and the source, provide a link to the Creative Commons licence, and indicate if changes were made. The images or other third party material in this article are included in the article's Creative Commons licence, unless indicated otherwise in a credit line to the material. If material is not included in the article's Creative Commons licence and your intended use is not permitted by statutory regulation or exceeds the permitted use, you will need to obtain permission directly from the copyright holder. To view a copy of this licence, visit http://creativecommons.org/licenses/by/4.0/.

\section{References}

Agathokleous A, Christodoulou S (2016) Vulnerability of urban water distribution networks under intermittent water supply operations. Water Resour Manag 30:4731-4750. https://doi.org/10.1007/s11269-016-1450-3

Ameyaw EE, Memon FA, Bicik J (2013) Improving equity in intermittent water supply systems. J Water Supply Res T 62(8):552-562. https://doi.org/10.2166/aqua.2013.065

Andey SP, Kelkar PS (2009) Influence of intermittent and continuous modes of water supply on domestic water consumption. Water Resour Manag 23:2555-2566. https://doi.org/10.1007/s11269-008-9396-8

Arregui F, Cabrera E, Cobacho R (eds) (2006) Integrated Water Meter Management. IWA Publishing, London

Cabrera-Bejar JA, Tzatchkov VG (2009) Inexpensive modeling of intermittent service water distribution networks. World Environ Water Resour Congr 2009:295-304. https://doi.org/10.1061/41036(342)29

Campisano A, Gullotta A, Modica C (2018) Using EPA-SWMM to simulate intermittent water distribution systems Using EPA-SWMM to simulate intermittent water distribution systems. Urban Water J 15(10):925933. https://doi.org/10.1080/1573062X.2019.1597379

Cobacho R, Arregui F, Cabrera E, Cabrera E (2008) Private water storage tanks: evaluating their inefficiencies. Wat Prac Technol. https://doi.org/10.2166/wpt.2008.025

Creaco E, Pezzinga G (2018) Comparison of algorithms for the optimal location of control valves for leakage reduction in WDNs. Water 10(4):466. https://doi.org/10.3390/w10040466

Creaco E, Walski T (2017) Economic analysis of pressure control for leakage and pipe burst reduction. J Water Resour Plan Manag 143(12):04017074. https://doi.org/10.1061/(ASCE)WR.1943-5452.0000846

Criminisi A, Fontanazza CM, Freni G, La Loggia G (2009) Implementation of a numerical model for the evaluation of potential apparent losses in a distribution network. Wat Sci Technol 60(9):2373-2382

De Marchis M, Fontanazza CM, Freni G, La Loggia G, Napoli E, Notaro V (2010) A model of the filling process of an intermittent distribution network. Urban Water J 7(6):321-333. https://doi.org/10.1080/ 1573062 X.2010.519776 
De Marchis M, Fontanazza CM, Freni G, La Loggia G, Napoli E, Notaro V (2011) Analysis of the impact of intermittent distribution by modelling the network-filling process. J Hydroinf 13(3):358. https://doi. org/10.2166/hydro.2010.026

De Marchis M, Fontanazza CM, Freni G, Milici B, Puleo V (2014) Experimental investigation for local tank inflow model. Procedia Eng 89:656-663. https://doi.org/10.1016/j.proeng.2014.11.491

De Marchis M, Milici B, Freni G (2015) Pressure-discharge law of local tanks connected to a water distribution network: Experimental and mathematical results. Water (switzerland) 7(9):4701-4723. https://doi. org/10.3390/w7094701

Deb K, Pratap A, Agarwal S, Meyarivan T (2002) A fast and elitist multiobjective genetic algorithm NSGAII. IEEE Trans. Evol. Comput 6(2):182-197

Farina G, Creaco E, Franhini M (2014) Using EPANET for modelling water distribution systems with users along the pipes. Civ Eng Environ Syst 31(1):36-50

Fontanazza CM, Freni G, La Loggia G (2007) Analysis of intermittent supply systems in water scarcity conditions and evaluation of the resource distribution equity indices. WIT Trans Ecol Environ 103:635644. https://doi.org/10.2495/WRM070591

Galaitsi SE, Russell R, Bishara A, Durant JL, Bogle J, Huber-Lee A (2016) Intermittent domestic water supply: a critical review and analysis of causal-consequential pathways. Water (Switzerland). https://doi. org/10.3390/w8070274

Gottipati PVKSV, Nanduri UV (2014) Equity in water supply in intermittent water distribution networks. Water Environ J 28(4):509-515. https://doi.org/10.1111/wej.12065

Gullotta A, Butler D, Campisano A, Creaco E, Farmani R, Modica C (2021) Optimal location of valves to improve equity in intermittent water distribution systems. J Water Resour Plan Manag. https://doi.org/ 10.1061/(ASCE)WR.1943-5452.0001370

Hardoy JE, Mitlin D, Satterthwaite D (2001) Environmental Problems in an Urbanizing World: Finding Solutions for Cities in Africa. Asia and Latin America, Earthscan, London

Ilaya-Ayza AE, Benítez J, Izquierdo J, Pérez-García R (2017a) Multi-criteria optimization of supply schedules in intermittent water supply systems. J Comput Appl Math 309, 695-703

Ilaya-Ayza AE, Martins C, Campbell E, Izquierdo J (2017b) Implementation of DMAs in intermittent water supply networks based on equity criteria. Water 9(11):851

Klingel P (2012) Technical causes and impacts of intermittent water distribution. Water Sci Technol Water Supply 12(4):504-512. https://doi.org/10.2166/ws.2012.023

Kumpel E, Nelson KL (2015) Intermittent water supply: prevalence, practice, and microbial water quality. Environ Sci Technol 2016, 50(2):542-553. ACS Publications. https://doi.org/10.1021/acs.est.5b03973

Manish S, Buchberger SG (2012) Role of Satellite Water Tanks in Intermittent Water Supply System Manish. Environmental, World Program, Environmental Engineering, (Yepes 2001), 944-951. https://doi. org/10.1061/9780784412312.096

McIntosh AC, Yñiguez CE (1997) Second Water Utilities Data Book: Asia and Pacific Region. Asian Development Bank, Manila

Mohapatra S, Sargaonkar A, Labhasetwar PK (2014) Distribution network assessment using EPANET for intermittent and continuous water supply. Water Resour Manag 28:3745-3759. https://doi.org/10.1007/ s11269-014-0707-y

Mokssit A, de Gouvello B, Chazerain A, Figuères F, Tassin B (2018) Building a methodology for assessing service quality under intermittent domestic water supply. Water 10(9):1164. https://doi.org/10.3390/W10091164

Pezzinga G, Gueli R (1999) Discussion of "Optimal location of control valves in pipe networks by genetic algorithm.” J Water Resour Plan Manag 125:65-67

Rossman LA (2015) Storm Water Management Model User's Manual Version 5.1. United States Environment Protection Agency, (September), 353

Simukonda K, Farmani R, Butler D (2018) Intermittent water supply systems: causal factors, problems and solution options. Urban Water J 15(5):488-500. https://doi.org/10.1080/1573062X.2018.1483522

Vairavamoorthy K, Gorantiwar SD, Mohan S (2007) Intermittent water supply under water scarcity situations. Water Int 32(1):121-132. https://doi.org/10.1080/02508060708691969

Publisher's Note Springer Nature remains neutral with regard to jurisdictional claims in published maps and institutional affiliations. 


\section{Authors and Affiliations}

\section{Aurora Gullotta $^{1}$ (D) Alberto Campisano ${ }^{1} \cdot$ Enrico Creaco $^{2} \cdot$ Carlo Modica $^{1}$}

Alberto Campisano

alberto.campisano@unict.it

Enrico Creaco

creaco@unipv.it

\section{Carlo Modica}

carlo.modica@unict.it

1 Department of Civil Engineering and Architecture, University of Catania, Viale Andrea Doria, 6, 95125 Catania, Italy

2 Department of Civil Engineering and Architecture, University of Pavia, Via Ferrata, 3, 27100 Pavia, Italy 